\title{
Perspectives on the relationship of renal disease and coronavirus disease 2019
}

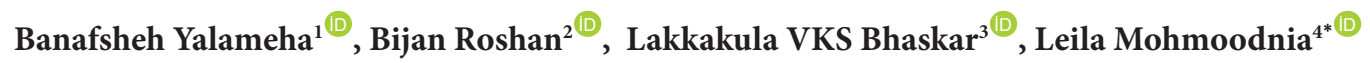 \\ ${ }^{1}$ Nickan Research Institute, Isfahan, Iran \\ ${ }^{2}$ Division of Nephrology, Scripps Clinic, La Jolla, California, USA \\ ${ }^{3}$ Department of Zoology, Guru Ghasidas Vishwavidyalaya, Bilaspur, India \\ ${ }^{4}$ Cancer Research Center, Shahrekord University of Medical Sciences, Shahrekord, Iran
}

\section{A R T I C L E I N F O}

Article Type:

Review

\section{Article History:}

Received: 10 April 2020

Accepted: 20 April 2020

Published online: 27 April 2020

Keywords:

Coronavirus disease 2019

Chronic kidney disease

Acute kidney injury

COVID-19

\begin{abstract}
A B S T R A C T
Coronavirus disease 2019 (COVID-19) is now a pandemic and its death toll is rocketing up. Patients with acute kidney injury (AKI) and chronic kidney disease (CKD) are at high risk of developing COVID-19 complications and COVID-19 infection can also lead to renal dysfunction. Considering the importance of kidney function in COVID-19 patients, the present review is aimed to dig into the available evidence about kidney and COVID-19. We summarize the mechanisms underlying the renal injury in COVID-19 patients, and treatment strategies in dialysis and kidney transplant patients. We conclude, it is imperative to highlight the early monitoring of patients with AKI and carefully control kidney function during severe acute respiratory syndrome coronavirus 2 (SARSCoV-2) infection.
\end{abstract}

Implication for health policy/practice/research/medical education:

It is imperative to highlight the early monitoring of patients with AKI and carefully control kidney function during severe acute respiratory syndrome coronavirus 2 (SARS-CoV-2) infection.

Please cite this paper as: Yalameha B, Roshan B, Bhaskar LVKS, Mohmoodnia L. Perspectives on the relationship of renal disease and coronavirus disease 2019. J Nephropharmacol. 2020;9(2):e22. DOI: 10.34172/npj.2020.22

\section{Introduction}

Coronaviridae family of viruses can cause diseases in mammals and birds, and possess enveloped particles containing single-stranded and positive-sense RNA. Coronavirus infection can lead to the diseases ranging from a mild condition such as common cold to severe diseases including severe acute respiratory syndrome coronavirus (SARS-CoV), Middle East respiratory syndrome coronavirus (MERS-CoV) and severe acute respiratory syndrome coronavirus 2 (SARS-CoV-2), a novel coronavirus emerged in Wuhan city, China (1, 2). Coronavirus disease 2019 (COVID-19) pandemic continues to expand quickly all over the world. The virus is transmitted through the same mechanisms as of influenza virus, from person to person through sneezing and coughing or contact with the secretion of infected persons. COVID-19 disease is more severe in the elderly, and persons with other chronic diseases such as chronic respiratory disease, diabetes, cardiovascular disease, hypertension, and renal injury (3). The most common symptom and signs of COVID-19 illness include fatigue, fever, and dry cough, as well as sputum production, headache, hemoptysis, diarrhea, dyspnea, and lymphopenia (4). Numerous trials are underway to identify effective drug regimens for COVID-19. The development of preventative vaccine or the discovery of novel drug candidates are in early phases. However, some broad-spectrum drugs are in use to mitigate the infection in patients with COVID-19 (5). A minority of patients develop multi-organ failure which aggravates COVID 19 mortality rate. It is estimated that organ dysfunction in patients with COVID-19 occurs in about $33 \%$, of which $3-7 \%$ are related to acute kidney injury (AKI) $(6,7)$. Old data from SARS and MERS-CoV infections have reported AKI development in 5\%-15\% cases (8). COVID-19 progression leads to renal dysfunction or renal injury as 
well as respiratory system injury (9). Given the importance of kidney function in COVID-19 patients, the present review is allocated to focus on the available evidence of renal disease and COVID-19.

\section{COVID-19 and renal impairment}

Patients with renal injury are at high risk of developing COVID-19 and AKI is an important risk factor for COVID-19 patients (8). Furthermore, renal impairment is one of the complications of SARS-CoV-2 infection. A large prospective study demonstrated that kidney impairment is more prevalent among hospitalized COVID-19 patients and is also associated with increased in-hospital death. Frequently COVID-19 patients, at the time of admission have proteinuria $(44 \%)$, hematuria $(26.9 \%)$, increased blood urea nitrogen (14.1\%), and increased plasma creatinine (15.5\%) (10). During this study, 3.2\% of patients developed AKI in the early days. This study emphasized the need for early interventions such as proper hemodynamic support and abstinence of nephrotoxic drugs as well as performing urine analysis in patients with COVID-19 to prevent kidney injury (10). In contrast to this survey, a study found that AKI is rare in COVID-19 and SARSCoV-2 infection does not lead to renal disturbance or exacerbation of chronic kidney disease (CKD) in COVID-19 patients (11). Hong et al, which evaluated the incidence of early renal injury in COVID-19 patients demonstrated the presence of abnormalities in levels of estimated glomerular filtration rate $(66.7 \%)$, creatinine clearance $(41.7 \%)$, and increased microalbuminuria (41.7\%), without significant abnormalities in blood urea nitrogen and plasma creatinine. They sound that the measurement of urine microalbumin, a1-microglobulin, urine immunoglobulin-G, and urine transferrin are more helpful in the diagnosis of early renal injury in COVID-19 patients (12).

Available data suggest that SARS-CoV-2 infection can have a direct cytotoxic effect on renal tubules and cause acute renal failure. Retrospective analysis of 85 patients with COVID-19 demonstrated that $27.06 \%$ of patients developed acute renal failure, especially in elder patients. Furthermore, kidney tissue examinations of postmortem specimens confirmed lymphocyte infiltration, severe acute tubular necrosis, and accumulation of viral nucleocapsid protein antigen in kidney tubules (13). The presence of SARS-CoV-2 virus particles in urine of COVID-19 patients might be due to penetration of viral particles through glomerular barrier (14). It is also reported that $51.67 \%$ of patients affected by novel coronavirus pneumonia had proteinuria since the severity of pneumonia was directly associated with levels of urine protein (15).

\section{COVID-19 and kidney transplant recipients}

Infections are a leading cause of morbidity and mortality in renal allograft recipients throughout the posttransplant course. Viruses are the most common causes of opportunistic infection after transplantation. Different factors that promote active invasive viral infection after organ transplantation include inflammation, graft rejection, tissue injury, and immune suppression (16). Previous studies have reported the SARS-CoV and MERS-CoV infections in transplant recipients $(17,18)$. In the current pandemic, SARS-CoV-2 infection has been reported in kidney transplant patients from China and Spain $(19,20)$. Reduction of immunosuppressive agents, along with low dose methylprednisolone-based regimes could improve COVID-19 pneumonia in a renal transplant recipient with long-term immunosuppressive therapy (21). Although there is not much data available on the incidence of COVID-19 in transplant recipients, it is recommended to follow preventive modalities and guidelines to prevent the spread of the disease $(22,23)$.

\section{COVID-19 and dialysis patients}

COVID-19 is a serious threat for dialysis patients in hemodialysis (HD) centers. Dialysis patients are more vulnerable to SARS-CoV-2 infection than the general people, due to thrice-weekly outside exposure for HD, older age and underlying chronic conditions (24). The study by Ma et al on $230 \mathrm{HD}$ patients and 33 staff members of $61 \mathrm{HD}$ centers in Wuhan confirmed the presence of COVID-19 infection in 37 of HD patients and 4 staff members. Among 37 COVID-19 infected HD patients, death occurred in 6 cases that was presumably due to cardiovascular, cerebrovascular diseases, and hyperkalemia but not exclusively due to COVID-19 pneumonia (25). Despite higher level of inflammatory cytokines in HD patients, compared to controls, lower serum level of inflammatory cytokines in COVID-19 patients on HD compared to other COVID-19 was detected. Additionally, HD patients with COVID-19 showed lower frequency of lymphocytes in peripheral blood mononuclear cells than other COVID-19 patients (25). Currently, the risk of SARS-CoV-2 infection transmission to HD patients and their families, medical staff, workers, and others is significantly high in HD centers (8). Therefore, the Taiwan society of nephrology (26), the Chinese society of nephrology (27), and the Centers for Disease Control and Prevention (28) have published guidelines for HD centers for the COVID-19 pandemic. As the prevention, protection, screening, isolation, and distribution are basic principles in the reduction and containment of the COVID-19 in HD centers, the management of dialysis patients with COVID-19 must be conducted based on standard protocols (29).

Mechanisms of renal injury in COVID-19

Recent studies revealed that renal dysfunction during SARS-CoV-2 infection is closely related to death in severe cases of COVID-19 patients. Although the exact mechanism is not fully clarified, it is possible that the expression pattern of angiotensin-converting enzyme 2 
(ACE2) can be associated with cellular susceptibility of SARS-CoV infection (30). SARS-CoV-2 enters into cells using the ACE2 receptor and cellular transmembrane serine proteases (TMPRSSs) as a co-receptor. ACE2, as a membrane-bound aminopeptidase, is highly expressed in the lungs, heart, intestine, kidneys and plays a fundamental role in the immune and cardiovascular systems and renal function $(31,32)$. The penetration of SARS-CoV-2 virus into the renal tubular cells, by binding to ACE2, induces cytotoxicity and renal function impairment (33). Singlecell RNA sequencing analysis of kidney cells has revealed that ACE2 is expressed along with TMPRSSs in proximal straight tubule cells and podocytes, indicating that the kidney cells are exposed to SARS-CoV-2 infection. TMPRSSs activate the spike protein of the virus surface for membrane fusion into host cells (34).

The cytokine storm syndrome involved in pathogenesis of the acute respiratory distress syndrome (ARDS) and various organs failure during SARS-CoV infection, seems to be related to enormous inflammatory reaction. The viral replication in targeted organs, including kidneys, induces systematic viral sepsis and systematic inflammatory responses, and subsequently cell damage in multiple organs (35). Additionally, SARS-CoV-2 infection activates cytokine cascade through releasing pro-inflammatory cytokines ( IL-4, IL-10, IL-1b, IFN-c, IP-10 and MCP-1) and chemokines (CCL2, CCL3, CCL5, CXCL1, CXCL8 and CXCL9), thereby resulting in the death of patients, as observed in SARS-CoV and MERS-CoV infections (36, 37). In addition, renal failure in COVID-19 patients may occur due to rhabdomyolysis, hypoxemia, dehydration, presence of underlying diseases, and improper consumption of non-steroidal anti-inflammatory drugs (Figure 1) $(38,39)$.

\section{ACE2-based therapeutic strategies}

Renal disorders, which initially appeared as mild abnormalities, may later be diagnosed as severe AKI in a significant proportion of patients. Since the progression of AKI in COVID-19 patients is an important prognostic factor, patients may be treated with some more directive interventions (9). Findings have suggested that the kidney cells are one of the target organs of COVID-19 virus, due to the expression of ACE2 and TMPRSS2. Agents targeting virus spike protein, protease TMPRSS2, and ACE2 receptor are to emerging as potential clinical strategies for prevention and therapy (40). In vitro studies using Vero-E6 monkey kidney cell line, demonstrated that SARS-CoV replication is blocked by a soluble form of ACE2 (41). Hence, it has been assumed that the soluble recombinant human ACE2 protein may be a therapeutic option to combat or limit SARS-CoV-2 infection progression (42). In support of this hypothesis, a previous study on an animal model has illustrated the beneficial effect of small ACE2 variants in the improvement of AKI by regulating kidney renin-angiotensin system activity (43). Further studies in engineered human organoids, including kidney organoids, revealed that the human recombinant soluble ACE2 (hrsACE2) can block the growth of SARS-CoV-2 in the early stages of infection (44). In addition, a clinically proven TMPRSS2 inhibitor, named camostat mesylate, prevents the cell entry of SARS-CoV-2 and might constitute a treatment option for COVID-19 (45).

\section{Conclusion}

COVID-19 virus attacks the cells expressing ACE2 and induces multiple organ injury. Kidney injury caused by COVID-19 increases mortality and morbidity substantially. Close monitoring of patients renal function, avoidance of nephrotoxins, and minimizing studies and interventions that can potentially harm kidneys, are especially important. In the absence of proven established drug regimens, aggressive supportive measures are needed in caring for patients with COVID 19 multiorgan failure. Still much further studies are warranted to reveal more and newer information on our uncharted understanding of this disease.

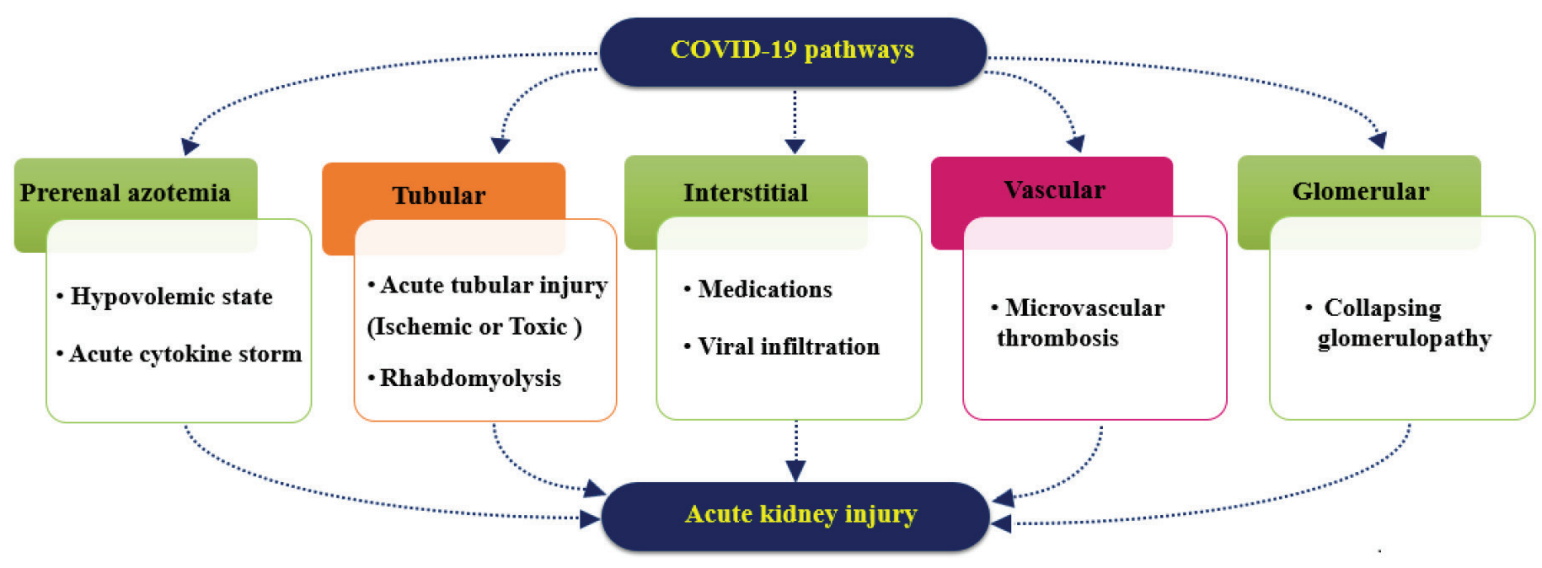

Figure 1. COVID-19 -induced acute kidney injury. 


\section{Authors' contribution}

BY and LM prepared the primary draft. LVKSB and BR edited the paper. All authors read and signed the final paper.

\section{Conflicts of interest}

Authors who have no conflicts of interest to declare.

\section{Ethical considerations}

Ethical issues (including plagiarism, data fabrication, double publication) have been completely observed by the authors.

\section{Funding/Support}

There was not financial support.

\section{References}

1. Lu R, Zhao X, Li J, Niu P, Yang B, Wu H, et al. Genomic characterisation and epidemiology of 2019 novel coronavirus: implications for virus origins and receptor binding. Lancet. 2020;395:565-74.

2. Zhu N, Zhang D, Wang W, Li X, Yang B, Song J, et al. A novel coronavirus from patients with pneumonia in China, 2019. N Engl J Med. 2020; 382:727-733. doi: 10.1056/ NEJMoa2001017.

3. Heymann DL, Shindo N. COVID-19: what is next for public health? Lancet. 2020;395(10224):542-5.

4. Rothan HA, Byrareddy SN. The epidemiology and pathogenesis of coronavirus disease (COVID-19) outbreak. J Autoimmun. 2020;109:102433. doi: 10.1016/j. jaut.2020.102433.

5. Lu H. Drug treatment options for the 2019-new coronavirus (2019-nCoV). Biosci Trends. 2020;14:69-71. doi: 10.5582/ bst.2020.01020.

6. Huang C, Wang Y, Li X, Ren L, Zhao J, Hu Y, et al. Clinical features of patients infected with 2019 novel coronavirus in Wuhan, China. Lancet. 2020;395:497-506. doi: 10.1016/ S0140-6736(20)30183-5.

7. Chen N, Zhou M, Dong X, Qu J, Gong F, Han Y, et al. Epidemiological and clinical characteristics of 99 cases of 2019 novel coronavirus pneumonia in Wuhan, China: a descriptive study. Lancet. 2020;395:507-13. doi: 10.1016/ S0140-6736(20)30211-7.

8. Naicker S, Yang CW, Hwang SJ, Liu BC, Chen JH, Jha V. The novel coronavirus 2019 epidemic and kidneys. Kidney Int. 2020. doi: 10.1016/j.kint.2020.03.001.

9. Li Z, Wu M, Yao J, Guo J, Liao X, Song S, et al. Caution on Kidney Dysfunctions of COVID-19 Patients. MedRxiv. 2020. doi:10.1101/2020.02.08.20021212.

10. Cheng Y, Luo R, Wang K, Zhang M, Wang Z, Dong L, et al. Kidney impairment is associated with in-hospital death of COVID-19 patients. MedRxiv. 2020. doi: 10.1101/2020.02.18.20023242.

11. Wang L, Li X, Chen H, Yan S, Li D, Li Y, et al. Coronavirus disease 19 infection does not result in acute kidney injury: an analysis of 116 hospitalized patients from Wuhan, China. Am J Nephrol. 2020. doi: 10.1159/000507471.

12. Hong Xw, Chi Zp, Liu Gy, Huang H, Guo Sq, Fan Jr, et al.
Analysis of early renal injury in COVID-19 and diagnostic value of multi-index combined detection. MedRxiv. 2020. doi: 10.1101/2020.03.07.20032599.

13. Diao B, Feng Z, Wang C, Wang H, Liu L, Wang C, et al. Human kidney is a target for novel severe acute respiratory syndrome coronavirus 2 (SARS-CoV-2) infection. MedRxiv. 2020. doi:10.1101/2020.03.04.20031120

14. Zhou P, Yang XL, Wang XG, Hu B, Zhang L, Zhang W, et al. A pneumonia outbreak associated with a new coronavirus of probable bat origin. Nature. 2020;579:270-3.

15. Xie Z, Bao J, Cai Z, Liu S, Chen H, Qi J, et al. Clinical Characteristics of 60 COVID-19-Infected Patients with or Without Renal Injury In Hangzhou, China. Xie, Zhijun and Bao, Jianfeng and Cai, Zhaobin and Liu, Shourong and Chen, Haiping and Qi, Jianjiang and Yu, Jianhua and Guo, Jianchun and Miu, Liangbin and Li, Zhaoyi and Sun, Jing and Yang, Hui and Huang, Lin and Tang, Yujun and Li, Zhiyu and Zhang, Yi and Huang, Jinsong and Wen, Chengping, Clinical Characteristics of 60 COVID19-Infected Patients with or Without Renal Injury In Hangzhou, China (February 19, 2020). Available at SSRN: https://ssrn.com/abstract=3541126.

16. Cukuranovic J, Ugrenovic S, Jovanovic I, Visnjic M, Stefanovic V. Viral infection in renal transplant recipients. ScientificWorldJournal. 2012;2012:820621. doi: $10.1100 / 2012 / 820621$.

17. Kumar D, Tellier R, Draker R, Levy G, Humar A. Severe acute respiratory syndrome (SARS) in a liver transplant recipient and guidelines for donor SARS screening. Am J Transplant. 2003;3:977-81.

18. AlGhamdi M, Mushtaq F, Awn N, Shalhoub S. MERS CoV infection in two renal transplant recipients: case report. Am J Transplant. 2015;15:1101-4. doi: 10.1111/ajt.13085.

19. Li Q, Cheng Q, Zhao Z, Zeng L, Zhu L, Guo W, et al. Novel Coronavirus Infection and Acute Kidney Injury in Two Renal Transplant Recipients: Case Report. Preprints 2020.

20. Guillen E, Pineiro GJ, Revuelta I, Rodriguez D, Bodro M, Moreno A, et al. Case report of COVID-19 in a kidney transplant recipient: Does immunosuppression alter the clinical presentation? Am J Transplant. 2020. doi: 10.1111/ ajt.15874.

21. Zhu L, Xu X, Ma K, Yang J, Guan H, Chen S, et al. Successful recovery of COVID-19 pneumonia in a renal transplant recipient with long-term immunosuppression. Am J Transplant. 2020. doi: 10.1111/ajt.15869.

22. Michaels MG, La Hoz RM, Danziger Isakov L, Blumberg EA, Kumar D, Green M, et al. Coronavirus disease 2019: Implications of emerging infections for transplantation. Am J Transplant. 2020. doi: 10.1111/ajt.15832.

23. Andrea G, Daniele D, Barbara A, Davide M, Laura A, Paolo R, et al. Coronavirus Disease 2019 and Transplantation: a view from the inside. Am J Transplant. 2020. doi: 10.1111/ ajt.15853.

24. Tang B, Li S, Xiong Y, Tian M, Yu J, Xu L, et al. Coronavirus Disease 2019 (COVID-19) Pneumonia in a Hemodialysis Patient. Kidney Med. 2020. doi: 10.1111/ajt.15853.

25. Ma Y, Diao B, Lv X, Zhu J, Liang W, Liu L, et al. 2019 novel coronavirus disease in hemodialysis (HD) patients: Report from one HD center in Wuhan, China. MedRxiv. 2020. doi: $10.1101 / 2020.02 .24 .20027201$. 
26. Hwang SJ. Guideline for dialysis facilities during COVID-19 outbreak. Taiwan Society of Nephrology. Available at: https://tinyurl.com/yx3zc5up. Accessed March 16, 2020.

27. Expert Team of Chinese Medical Association Nephrology Branch. Recommendations for prevention and control of novel coronavirus infection in blood purification center (room) from Chinese Medical Association Nephrology Branch. Chin J Nephrol. 2020;36:82-84.

28. Interim Additional Guidance for Infection Prevention and Control Recommendations for Patients with Suspected or Confirmed COVID-19 in Outpatient Hemodialysis Facilities. https://www.cdc.gov/coronavirus/2019-ncov/ healthcare-facilities/dialysis.html.

29. Basile C, Combe C, Pizzarelli F, Covic A, Davenport A, Kanbay M, et al. Recommendations for the prevention, mitigation and containment of the emerging SARS-CoV-2 (COVID-19) pandemic in haemodialysis centres. Nephrol Dial Transplant. 2020. doi: 10.1093/ndt/gfaa069.

30. Burchfield J. Renin-Angiotensin-Aldosterone System: Double-Edged Sword in COVID-19 Infection. Preprints 2020.

31. Guo L, Yu K, Li D, Yang H, Liu L, Fan J, et al. Potential Pathogenesis of Multiple Organ Injury in COVID-19. Preprints 2020. doi: 10.20944/preprints202003.0308.v1.

32. Tolouian R ZVS, Ghiyasvand S, Tolouian A, Ardalan MR. COVID-19 interactions with angiotensin-converting enzyme 2 (ACE2) and the kinin system; looking at a potential treatment. J Renal Inj Prev. 2020;9:e19. doi: 10.34172/jrip.2020.19

33. Fan C, Li K, Ding Y, Lu WL, Wang J. ACE2 expression in kidney and testis may cause kidney and testis damage after 2019-nCoV infection. MedRxiv. 2020. doi: 10.1101/2020.02.12.20022418.

34. Xu D, Zhang H, Gong HY, Chen JX, Ye JQ, Meng T, et al. Identification of a Potential Mechanism of Acute Kidney Injury During the Covid-19 Outbreak: A Study Based on Single-Cell Transcriptome Analysis. Preprints 2020.

35. Jin Y, Yang H, Ji W, Wu W, Chen S, Zhang W, et al. Virology, Epidemiology, Pathogenesis, and Control of COVID-19. Viruses. 2020;12:372.

36. Li X, Geng M, Peng Y, Meng L, Lu S. Molecular immune pathogenesis and diagnosis of COVID-19. J Pharm Anal.
2020. doi: $10.1016 /$ j.jpha.2020.03.001.

37. Fu Y, Cheng Y, Wu Y. Understanding SARS-CoV-2Mediated Inflammatory Responses: From Mechanisms to Potential Therapeutic Tools. Virol Sin. 2020. doi: 10.1007/ s12250-020-00207-4.

38. Menachery VD, Yount BL Jr, Debbink K, Agnihothram S, Gralinski LE, Plante JA, et al. A SARS-like cluster of circulating bat coronaviruses shows potential for human emergence. Nat Med. 2016;22:446. doi: 10.1038/nm0416446d.

39. Hamming I, Timens W, Bulthuis ML, Lely AT, Navis G, van Goor $\mathrm{H}$. Tissue distribution of ACE2 protein, the functional receptor for SARS coronavirus. A first step in understanding SARS pathogenesis. J Pathol. 2004;203:6317.

40. Deng YY, Zheng Y, Cai GY, Chen XM, Hong Q. Singlecell RNA sequencing data suggest a role for angiotensinconverting enzyme 2 in kidney impairment in patients infected with 2019-nCoV. Chin Med J. 2020. doi: 10.1097/ CM9.0000000000000783.

41. Li W, Moore MJ, Vasilieva N, Sui J, Wong SK, Berne MA, et al. Angiotensin-converting enzyme 2 is a functional receptor for the SARS coronavirus. Nature. 2003;426:450-4. doi: $10.1038 /$ nature02145.

42. Batlle D, Wysocki J, Satchell K. Soluble angiotensinconverting enzyme 2: a potential approach for coronavirus infection therapy? Clin Sci. 2020;134:543-5. doi: 10.1042/ CS20200163.

43. Wysocki J, Schulze A, Batlle D. Novel Variants of Angiotensin Converting Enzyme-2 of Shorter Molecular Size to Target the Kidney Renin Angiotensin System. Biomolecules. 2019;9:886. doi: 10.3390/biom9120886.

44. Monteil V, Kwon H, Prado P, Hagelkrüys A, Wimmer RA, Stahl M, et al. Inhibition of SARS-CoV-2 infections in engineered human tissues using clinical-grade soluble human ACE2. Cell. 2020. doi: 10.1016/j.cell.2020.04.004.

45. Hoffmann M, Kleine-Weber H, Schroeder S, Krüger N, Herrler T, Erichsen S, et al. SARS-CoV-2 cell entry depends on ACE2 and TMPRSS2 and is blocked by a clinically proven protease inhibitor. Cell. 2020;181:271-280.e8. doi: 10.1016/j.cell.2020.02.052.

Copyright $\odot 2020$ The Author(s); Published by Published by Society of Diabetic Nephropathy Prevention. This is an open-access article distributed under the terms of the Creative Commons Attribution License (http://creativecommons.org/licenses/by/4.0), which permits unrestricted use, distribution, and reproduction in any medium, provided the original work is properly cited. 